\title{
EFFICIENCY ENHANCEMENT OF SEA WAVES ENERGY CONVERTER VIA LEAN PRINCIPLES USING AN EFFECTIVE MECHANICAL MECHANISM
}

\author{
Khaled M. Khader and Omayama A. Nada \\ Production Engineering and Mechanical Design Department, Faculty of Engineering, Menoufia \\ University, Shebin El-kom, Menoufia, Egypt.
}

\begin{abstract}
:
The extracted crude oil from some world areas can be considered as the main pillar of industrial development. Regrettably, the rapid rate of depletion of this kind of energy's sources in addition to its bad environmental effect can decelerate the industrial progress rate. Consequently, more attention has been directed to generate the needed power from the sustainable clean resources, as a response to the worldwide increased energy demand accompanied with a rapid rate of crude oil consumption in addition to increased environmental consciousness. Seas and oceans waves' energy is one of the renewable clean and cheap energy resources. Many types of energy converters can be used to convert seas waves' energy into cheap electricity. Many of previous scientific work is dealing with the most effective wave's energy converters. Some of the published work preferred the oscillating water column (OWC) converter's usage than the other waves energy's converters, although OWC is dependent on Wells turbines which has relatively low efficiency. This paper deals with enhancing the performance of seas waves' energy converter via lean principles. Therefore, a prototype of the suggested mechanical mechanism has been built and tested which can be used instead of Wells turbine for providing the required motion to the generator.
\end{abstract}

Keywords: Renewable Energy, Oscillating Water Column, Mechanisms, Value Stream Mapping.

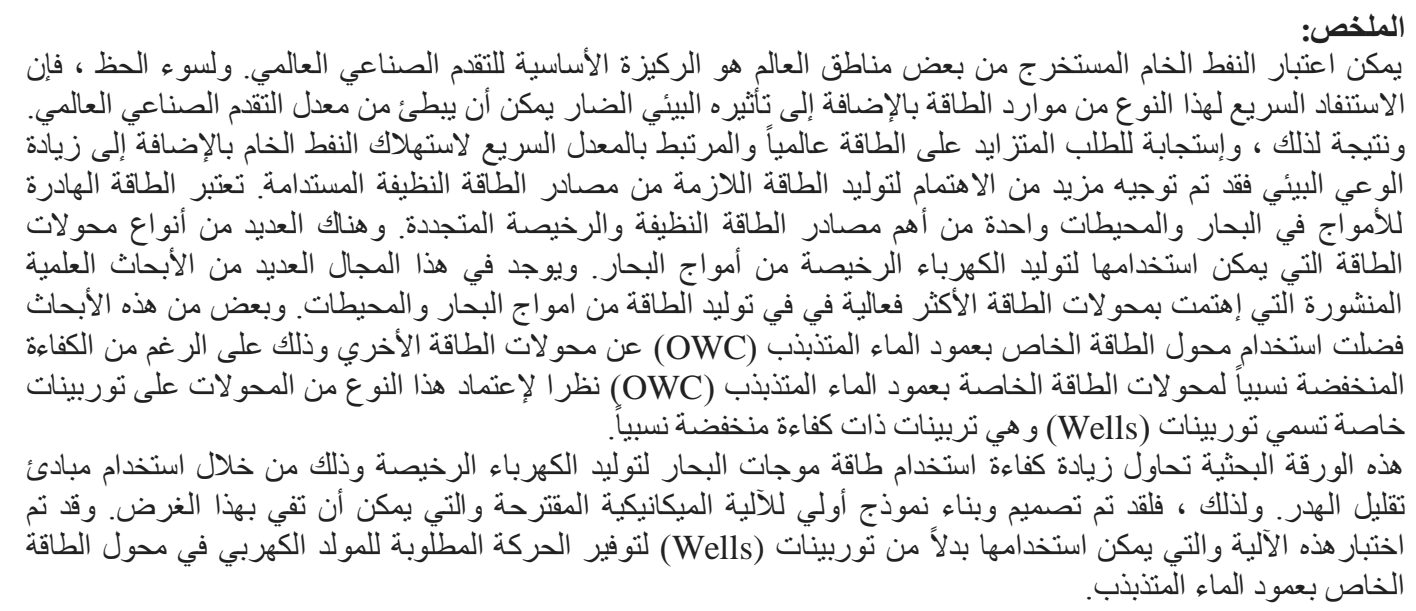

\section{INTRODUCTION}

Some of the African countries as Egypt are slightly modest in their resources of conventional energies as the crude oil compared with rich oil countries in the Gulf area. Consequently, exploiting clean and sustainable sources other than crude oil must be considered for assuring alternative energy supply in long term. Moreover, as a response to the worldwide increased demand for energy accompanied by rapid depletion of the fossil fuels as well as increased awareness of environmental concerns, more attention has been directed to clean and sustainable sources for power generation. Clean and sustainable sources as solar, wind and sea wave's energies can be considered as a compensatory source for filling the 
gap between the growing demand and the existing conventional energies in poor countries. Among those renewable and green sources, the oceans and seas waves may be considered as promising ones [1].

If wave energy can be extensively exploited, it may significantly contribute to the supply of electrical energy in coastal regions. Oceans and seas wave energy is characterized by its relatively consistent potential. This can be attributed to its high availability and predictability compared with other sources of renewable energy. The wide geographical distribution and the stability of the source, in addition to the limited environmental impacts tags wave energy as a strategic source of renewable energy [2, $3]$. This is due to the availability of seas' wave energy through most of day hours throughout the whole year. Conversely, the solar and wind energy are available for some hours daily especially on sunny and windy periods respectively.

Commonly, renewable clean energy can be produced using tidal motion or seas' wave. There are miscellaneous concepts and techniques for converting wave energy which are known as Wave Energy Converters (WEC). The different types of WEC have been identified and their designs, as well as operating principles, have been reviewed by several researchers [4-8]. Moreover, the world important projects for wave energy conversion have been highlighted and the challenges for commercial competitiveness have been reported [6,9]. Despite the diversity of technologies and the enormous research efforts in the field of wave energy conversion, researchers pointed out that those technologies have not yet reached the commercial maturity phase. This is owed to not only technical reasons but also economical ones [10].

For assuring long service life of the WEC components in the aggressive environment of oceans and seas, these components must have high endurance. For this reason, researches have not yet completely settled down to design a suitable economical WEC [11].

In general, the whole generated energy percentage using the common types of renewable energy is still modest around $10 \%$ compared with the conventional ones [12]. It is promising that the Egyptian authorities do their best to fill the energy shortage gap through increasing renewable energy usage from $5 \%$ in 2014 to be around $22 \%$ from the total energy in 2030 [13].

Many types of sea wave's energy converters can be used to transform the wave energy into electrical energy. These converters are using different operating ideas. Some of these are; oscillating bodies, power buoy, wave dragon, over-topping, pendulum gate, Bristol cylinder, pelamis and oscillating water column converters as presented in [14-22]. The operating idea of oscillating bodies converter is based on the relative motion between two parts which is similar to the power buoy operating idea, but oscillating bodies are immersed in the water while power buoy floats above water's surface. Likewise, over-topping converter is similar to wave dragon converter, but the first one has a submerged hanged reservoir using springs connected to the seabed for providing up and down water's motion inside a turbine fixed in its reservoir. However, wave dragon has a foundation fixed with the seabed for carrying its reservoir. Likewise, the pendulum gate gives a direct mechanical motion to the electrical generator in shallow water similar to the operating idea of Bristol cylinder which has a planar four bar mechanism. Also, pelamis converter can be used near to the shallow water. This converter consists of a set of semi-submerged hollow tubes. The relative motion between these tubes can provide the generator with the required mechanical motion.

Finally, the Oscillating Water Column (OWC) converter can be established near shore. It consists of a closed hollow chamber has an open area in its base to collect the moving water of sea waves. The collected water inside the chamber moves up and down related to the sea wave's motion. The surface of water inside the chamber pushes an air pocket up and down. This air pocket can pass through the Wells turbine to generate electricity. The Wells turbine is used to give continuous rotation regardless of the direction of air flow as in [22-28]. Each of these previous converters has its disadvantages and advantages. Hence, the decision of selecting the most appropriate converter suitable for an application can be considered as a critical decision in the generating power project's planning stage.

Each converter operating method characteristics have been investigated in addition to highlighting the main criteria for assessment of these methods. A multi-criteria model using analytic hierarchy process was developed for supporting the decision making process dealing with the selection process of the most proper method according to the designer's requirements [22]. In this model, seven main criteria have been considered in this model for evaluating the design alternatives, namely, safety, reliability, durability, performance, cost, interference with navigation and serviceability. Some of these main criteria are assessed by sub-criteria as; a possibility of power storage, efficiency, power quality, maintenance's ease, robustness, installation cost, the speed of repair, in addition to maintenance and operational costs. This model revealed that the oscillating water column converter is the most preferable converter for producing electricity from seas waves, despite the low efficiency of the Wells turbine as presented in [26-29]. 
This paper concerns with enhancing the performance of oscillating water column converter using lean principles for replacing the low-efficiency Wells turbine with an effective mechanical mechanism. Consequently, a prototype of the proposed mechanical mechanism has been built and tested for providing the required motion to the generator.

\section{Process Modeling using Value Stream MAPPING}

The Lean concept has originally started in Toyota Production Systems (TPS) and later it has been widely approved to be one of the most effective approaches for improving the performance in several industries. The ultimate objective of applying lean manufacturing principles is to eliminate waste by reducing the non-value activities in the processes [30-32]. Accordingly, the success of lean principles in manufacturing has encouraged other sectors to extend the concept to save their resource and achieve better performance. For instance, the principles of lean have applied in higher education [33], in medical services [34], call service centers [35], lean office management [36], and lean supply chain [37].

Particularly, one of the most extensively employed tools in lean implementation is Value Stream Mapping (VSM). Usually in lean manufacturing, the VSM is employed to observe the flow of material and information as the product proceeds through the production and this can effectively help in identifying the non-value added activities. Generally, the implementation of VSM can be achieved via two stages. The first one is mapping of the current state of the system, while the second one is the modified state in which the non-value added activities are minimized or eliminated, which is known as the future state. Several researchers proposed implementing the VSM for managing energy conception and this has been nominated as energy VSM [38-40]. In this research, the energy VSM tool will be extended to be applied to energy generation and the process cards included in the value stream map will only include the energy losses in each stage.

\section{A. Energy VSM (Current State):}

Analyzing the current design of the OWC converter, illustrated in Fig. 1, reveals that it can be modeled using value stream mapping. The current state value stream map, as shown in Fig. 2, consists of six stages (stage $i, i=1,2, \ldots, 6$ ). Each stage of index $i$ has an input energy $\mathrm{E}_{i-1}$ and output energy $\mathrm{E}_{i}$. The losses in each stage $\mathrm{L}_{i}$ is the difference between the input and output energies of that stage. These different stages can be explained as follows:

The first stage (Wave Collector) is concerned with gathering the sea or ocean wave via a concrete or rock walls designed as a v-shaped that have a wide opening and narrow connection to the OWC converter. This structure has the advantage of accelerating collected waves before entering the OWC converter. The losses during this stage $\left(\mathrm{L}_{1 j}\right)$, $j=1,2, \ldots, 4$ can be identified as losses due to:

$\mathrm{L}_{11}$ : turbulence in the water flow

$\mathrm{L}_{12}$ : friction between water and the collecting walls

$\mathrm{L}_{13}$ : rebound of waves resulted from impact with walls

$\mathrm{L}_{14}$ : sprinkled volatile spillage water

The second stage (Water Column Rise) entails water column rising inside the OWC chamber. The losses during this stage $\left(\mathrm{L}_{2 j}\right), j=1,2$ can be identified as losses due to:

$\mathrm{L}_{21}$ : decreasing the kinetic energy of moving water due to potential energy increase

$\mathrm{L}_{22}$ : friction between rising water and the chamber walls

While, in the third stage (Air Bucket Formation), the rising water column pushes the air bucket above it in order to press the air towards the Wells turbine. The losses during this stage $\left(\mathrm{L}_{31}\right)$ are due to the friction with the chamber walls. Meanwhile, the fourth stage (Air Rotates Turbine Blades) involves rotating the Wells turbine blades due to the action of the kinetic energy of the pushed air bucket. The losses during this stage $\left(\mathrm{L}_{4 j}\right), j=1,2,3$ can be identified as losses due to:

$\mathrm{L}_{41}$ : mechanical losses in the moving parts as bearings

$\mathrm{L}_{42}$ : friction between air and the blades surface

$\mathrm{L}_{43}$ : ineffective air flow between the moving blades (without hitting it)

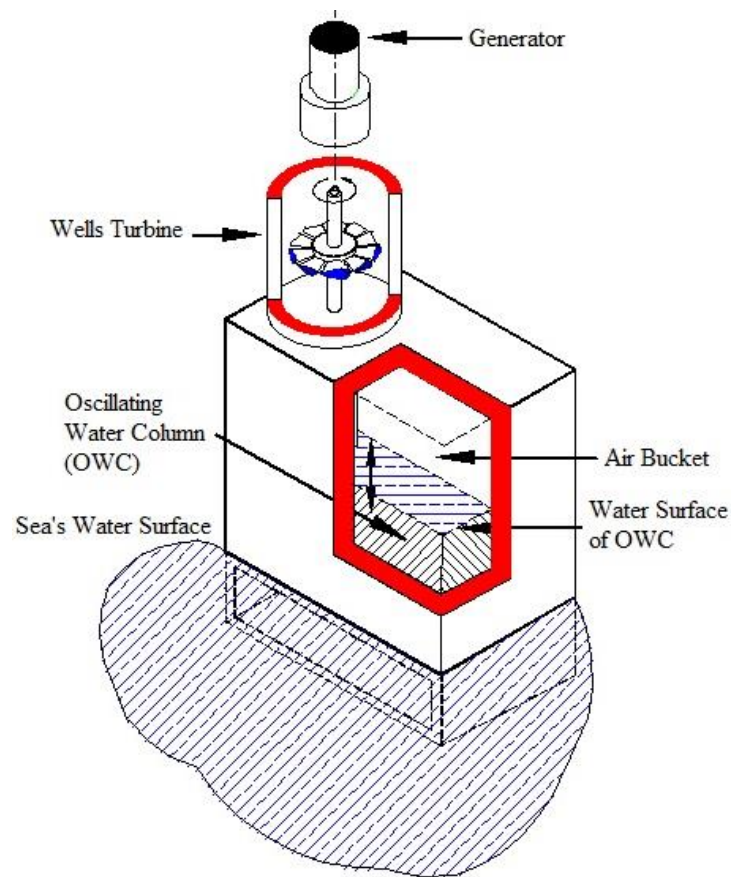

Fig. 1 Oscillating Water Column (OWC) converter 
On other hand, the fifth stage (Air Suction Rotates Turbine) entails rotating the Wells turbine blades due to the action of air suction resulting from declining sea waves. The losses through this stage $\left(\mathrm{L}_{5 j}\right), j=1,2$, 3 can be identified as:

$\mathrm{L}_{51}$ : mechanical losses in the moving parts as bearings

$\mathrm{L}_{52}$ : losses due to friction between air and the blades surface

$\mathrm{L}_{53}$ : losses due to ineffective air flow between the moving blades (without hitting it)

Finally, in the sixth stage (Electricity Generation), the rotation motion of the Wells turbine axis can be used for generating the required electricity. The losses during this stage $\left(\mathrm{L}_{61}\right)$ are due to the friction between the moving parts in addition to the electrical losses.

The losses through this stage $\left(\mathrm{L}_{6 j}\right), j=1,2$ can be identified as:
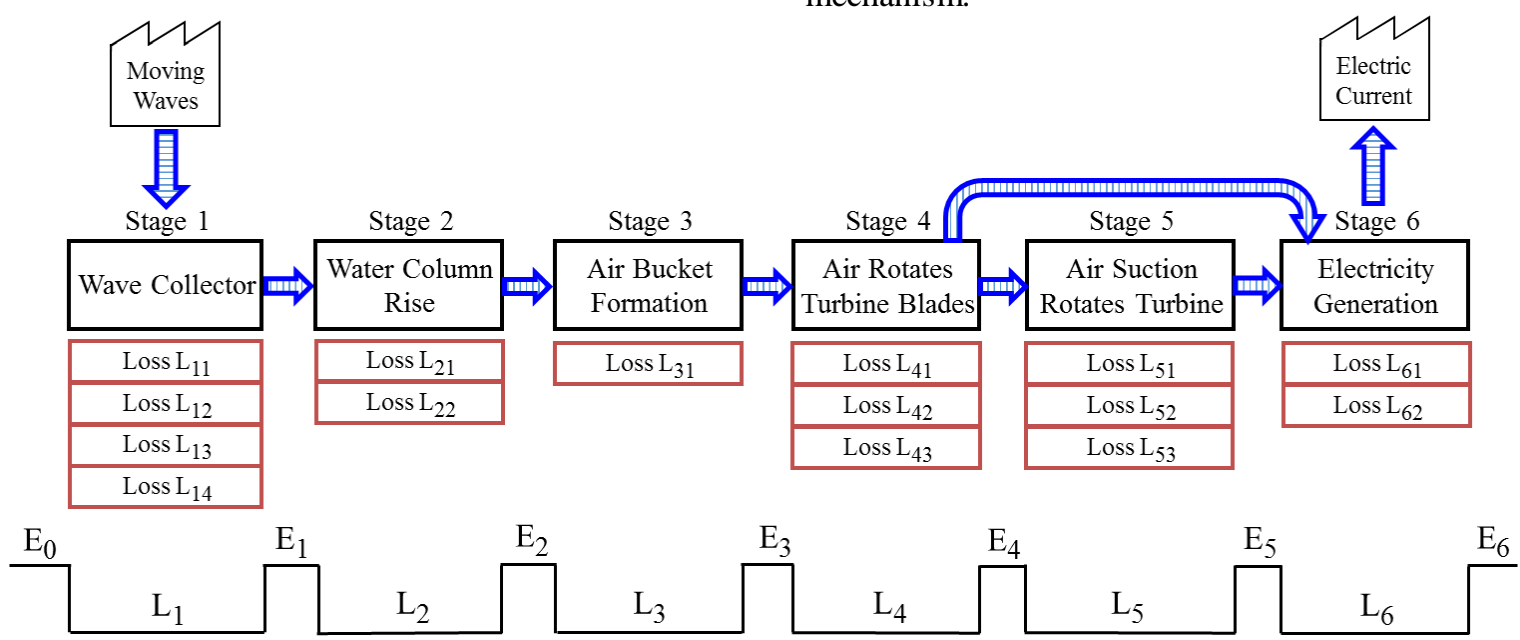

Fig. 2 Value stream mapping (Current state)
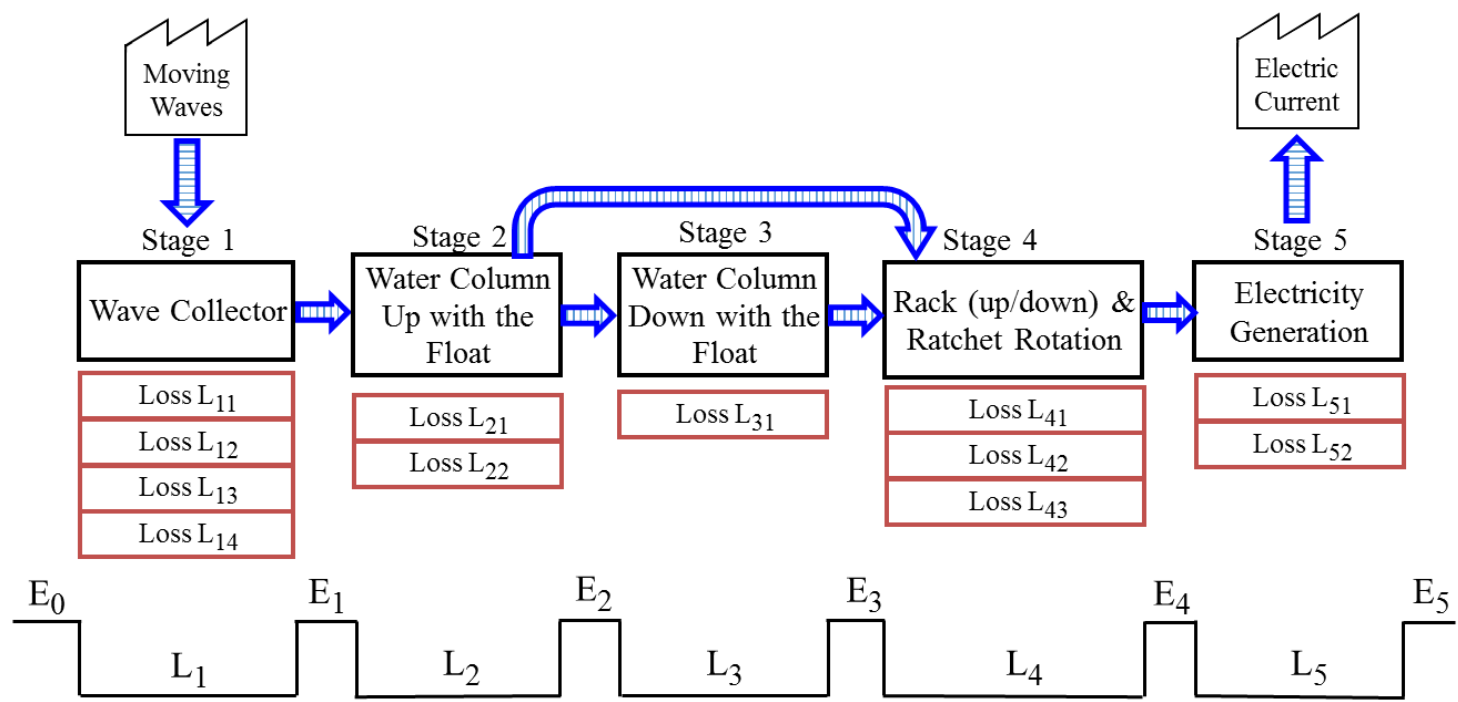

Fig. 3 Value stream mapping (Future state) 
This mechanism basically consists of a float placed on the water surface and attached to a rack (sliding block) rotates ratchet gears. The proposed mechanism will be explained in more details in the next section and it mainly has the advantage of providing ratchet gear which can rotate in the same direction whether the water column is rising or falling inside the chamber.

According to the modified design, the future state map comprises five stages. The first stage is the same as in the current state with the same losses. In the second stage, the water column is rising inside the chamber carrying a float on its surface and the losses are also the same as the current state. However, in the third stage, the water column is falling down with the float on its surface (Water Column Down with the Float). The losses associated with this stage are only the losses due to the friction with the chamber walls $\left(\mathrm{L}_{31}\right)$. On the other hand, the fourth stage (Rack Reciprocation and Ratchet Rotation) involves moving the rack up or down as affected by the rising or falling of the float which by its turn rotates the ratchet gear such that it is guaranteed to be in the same direction as it will be explained later. The losses during this stage $\left(\mathrm{L}_{4 j}\right), j=1,2,3$ are mostly mechanical losses that can be recognized as:

$\mathrm{L}_{41}$ : friction between rack and its guide

$\mathrm{L}_{42}$ : gear losses such as backlash

$\mathrm{L}_{43}$ : bearings losses

While, the fifth stage (Electricity Generation) is the same as the sixth stage in the current state map with the same losses.

$\mathrm{L}_{51}$ : mechanical losses in the moving parts as bearings

$\mathrm{L}_{52}$ : electrical losses

\section{The Suggested System for Enhancing THE PERFORMANCE OF OWC CONVERTER}

The performance of the OWC converter which is shown in Fig. 1 can be considered as a relatively low efficient system because of the Wells turbine usage. Therefore, an effective mechanical mechanism can be used instead of the Wells turbine for enhancing the performance of OWC converter. The suggested system consists of a floating block which moves up and down associated with the sea waves' motion as shown in Fig. 4. This floating block can be connected via another suitable vertical sliding block. This sliding block moves along a fixed vertical guide which is fixed with the sea's wave barrier near to shore.

Also, it carries double chains over its sides. A suitable two ratchet gears can be engaged in these chains. Moreover, these two gears can be rotated owing to the reciprocating motion of the sliding block. These ratchet gears are similar to the bicycle's ratchet sprocket. A special ratchet gears design presented in [43]. Generally, this type of ratchet gear can rotate its shaft in a certain rotation's direction as a positive action. On the other hand, it can be rotated freely in the other rotation's direction without driving its shaft. The direction of the positive action of the first ratchet gear is reverse of the second one of this suggested system. Hence, one of these two ratchet gears has a positive action associated with the upward movement of the sliding block, while the other ratchet gear has a positive action through downward movement of the sliding block. A suitable belt can be installed between two pulleys which are fixed with the two ratchet gears' shafts. Another belt can be used for transferring the existed continuous motion to the electrical generator.

The moving wave hits the wall of wave barrier with considerable energy. Hence, the water surface beside the barrier wall moves with upward motion carries the floating block. The kinetic energy $\left(E_{w}\right)$ of water which carries the floating block can be expressed as follows;

$$
E_{w}=\frac{\rho_{w}}{2} A_{f} v_{w}^{3}
$$

Where, $\left(\rho_{w}\right)$ is the sea's salty water density $\left(\rho_{w}=1025 \mathrm{Kg} / \mathrm{m}^{3}\right),\left(A_{f}\right)$ is the area of the floating block which touches the water surface and $\left(v_{w}\right)$ is the water column velocity. The resulted torque $(T)$ through water surface movement can be formulated as follows;

$$
T=\frac{E_{w}}{\omega}
$$

Where, $(\omega)$ is the angular velocity of ratchet gear's shaft which can expressed as a function in the velocity $\left(v_{w}\right)$ and the radius $\left(R_{g}\right)$ of ratchet gear as follows;

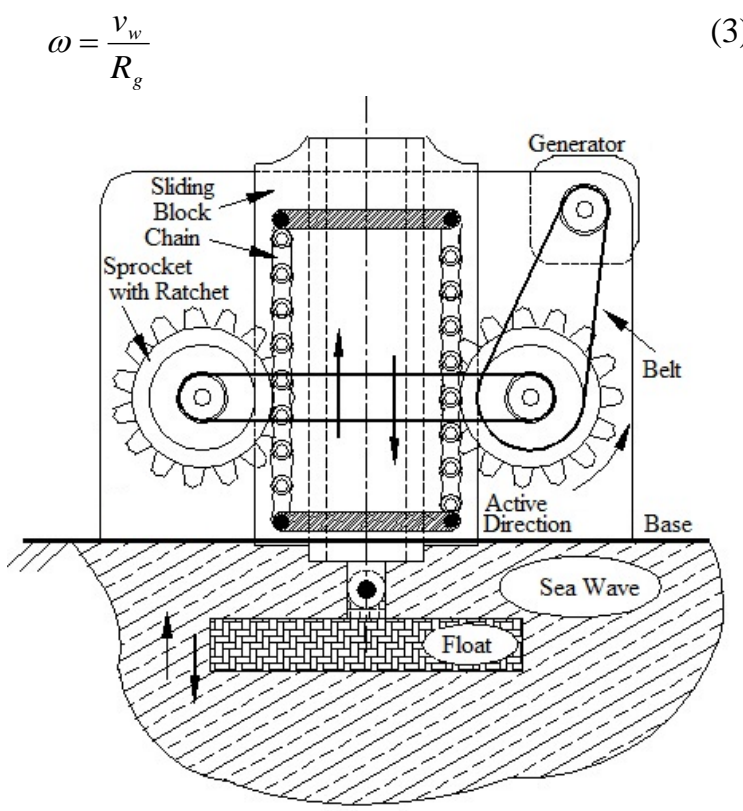

Fig. 4 Suggested system 


\section{SUgGeSTED System PROTOTYPE}

The layout of the experimental arrangement is shown in Fig. 5. This arrangement can be used to simulate the sea waves for testing the validity of the suggested system idea. The arrangement consists of two vertical connected stands. The first one has a movable container that can slide up and down along vertical guides by a reciprocating manual force through a wire connected to it. On the other hand, the second one has a fixed container. This fixed container is connecting to the movable container via a wide flexible tube. This tube is used for transferring the water from the higher container to the lower one owing to the movable container's movement. Hence, up and down motion of the water surface in the fixed container can be used to simulate the up and down sea wave's motion.

A prototype has been built according to the previous layout in order to simulate the motion of the sea waves. The prototype frame is manufactured from a suitable wood. Moreover, a plastic container is placed at a fixed level on the frame. Also, another plastic container is connected to the fixed one via a flexible tube as shown in Fig. 6. Also, a ratchet gears mechanism block is fixed in the frame. The sliding block of this mechanism is connected to a wooden float which is placed over the water surface in the fixed container. This ratchet gears mechanism is shown in Fig. 7.

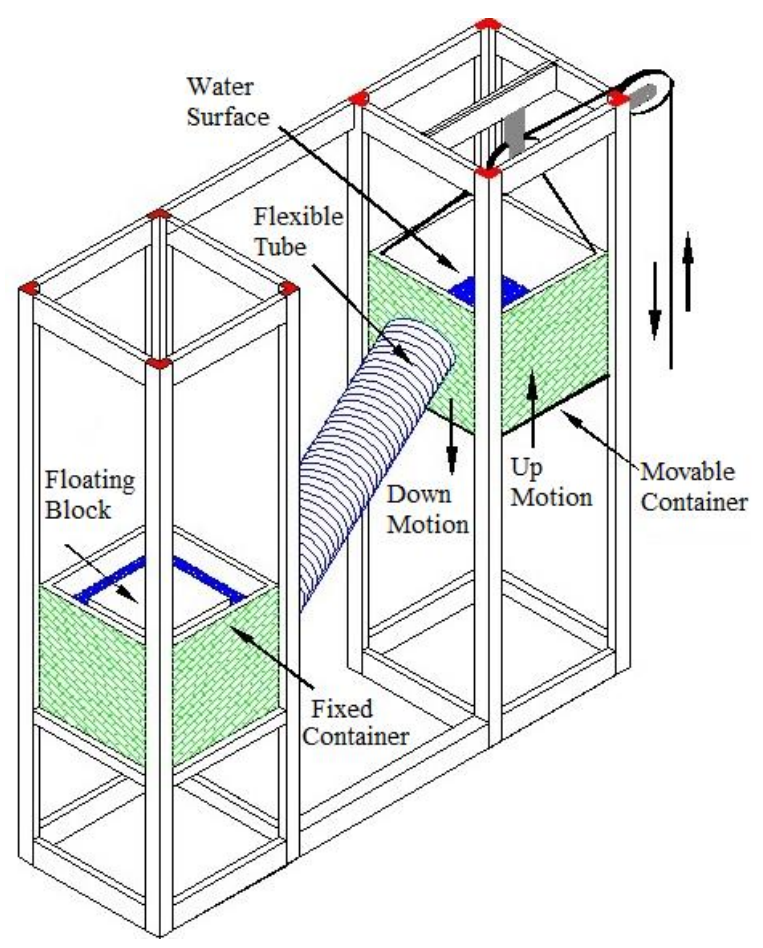

Fig. 5 Design of experimental arrangement

\section{Validity of the Suggested System}

The prototype indicates that the idea of the suggested system is valid for using it as a sea wave converter.

To simulate the sea waves' motion, two plastic containers with a cross section $(0.3 \times 0.3 \mathrm{~m})$ and a flexible tube of diameter equals $(0.1 \mathrm{~m})$ as a water connector are used. Furthermore, the resulted output torque of the ratchet gears mechanism is measured and compared with the theoretical ones for testing the converter efficiency enhancement. It has been observed that the measured torque and the theoretical one approximately have the same trend as illustrated in Fig 8. The ratio of the average of measured peak torques to the average of their corresponding theoretical ones is approximately $(0.68)$ via ratchet gears mechanism usage. One the other hand, the ratio of the old design was (0.49), according to the results of [22] that uses Wells turbine. Comparing these two ratios reveals that there is a $19 \%$ improvement which can be directly attributed to the new design.

\section{Conclusion}

Filling the gap between actual energy needs and the available ones recently became the main concern of authorities in most countries. Therefore, the world's attention has been focused on increasing the efficiency of generating energy from clean and sustainable energy sources such as solar, wind and sea wave's energy. Furthermore, the energy generated from oceans or sea waves is one of the cheapest renewable energy sources. Especially, the energy can be generated from this kind of renewable energy source almost all the time.

There are many energy converters that can be used for converting the sea wave's energy into mechanical or electrical energy. In this regard, many of published scientific work is concerning with the most effective wave's energy converters; some of these scientific work preferred the usage of the oscillating water column (OWC) converter which depends on the Wells turbine than the other wave's energy converters. But, this kind of energy converters still have serious disadvantage related to the relatively low efficiency of the Wells turbine.

Enhancing the seas waves' energy performance was the main concern of this paper. In this regard, lean principles have been applied in order to decrease the losses associated with the current design and to help in achieving a modified design that is capable of enhancing the (OWC) efficiency. By analyzing the current design using value stream mapping, it has been recommended that the Wells turbine has to be replaced with an effective mechanical mechanism. The proposed mechanism uses ratchet gears 
connected with a reciprocating sliding block. This sliding block is connected with floating block which can be placed above the moving sea water surface. This arrangement can directly convert the sea wave energy into mechanical energy.

An experimental prototype is used for testing the validity of the modified OWC converter using the ratchet gears mechanism. The efficiency of the suggested design has improved by $19 \%$ compared with the published results for the traditional OWC design that relies on Wells turbines.

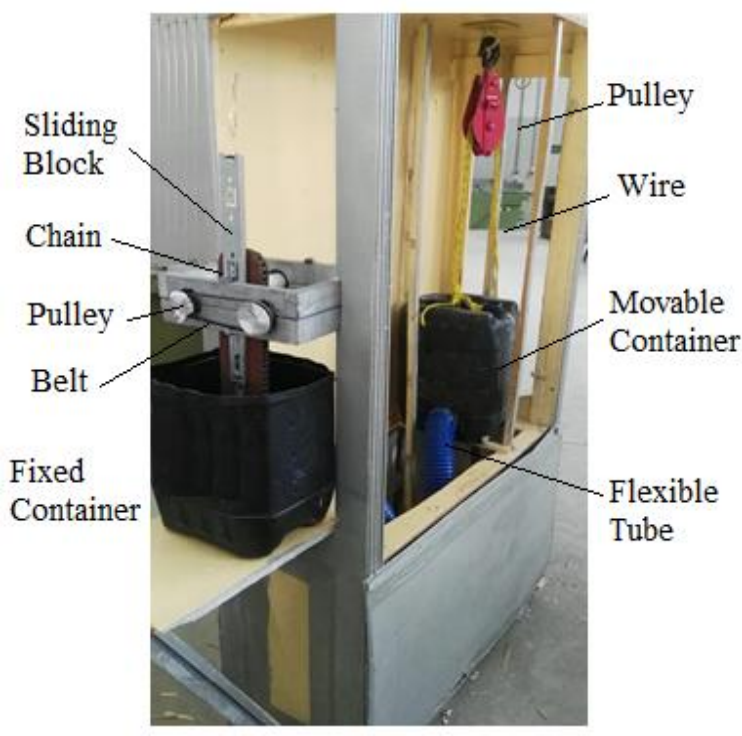

Fig. 6 Experimental prototype

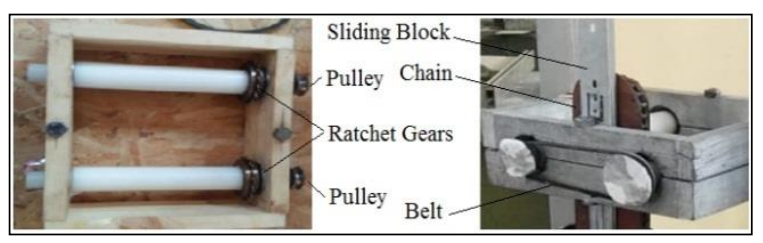

Fig. 7 Ratchet gears mechanism

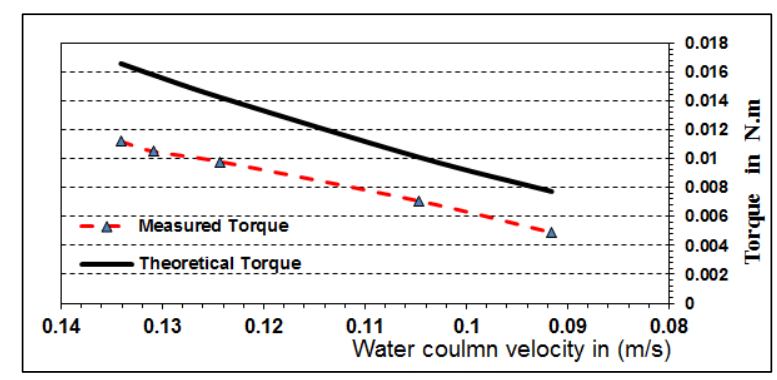

Fig. 8 Theoretical and measured torque using ratchet gears mechanism

\section{References}

[1] S. Astariz and G. Iglesias, "The economics of wave energy: A review", Renewable and Sustainable Energy Reviews, 45, pp. 397-408, (2015).

[2] G. Mork, S. Barstow, A. Kabuth, and M.T. Pontes, "Assessing the global wave energy potential", ASME 2010 29th International conference on ocean, offshore and arctic engineering, American Society of Mechanical Engineers, pp. 447-454, (2010).

[3] E. Tedeschi, M. Carraro, M. Molinas, and P. Mattavelli, "Effect of control strategies and power take-off efficiency on the power capture from sea waves", IEEE Transactions on Energy Conversion, 26(4), pp. 1088-1098, (2011).

[4] T. Thorpe, "An overview of wave energy technologies: status, performance and costs", Wave power: moving towards commercial viability, 26, pp. 50-120, (1999).

[5] J. Falnes, "A review of wave-energy extraction", Marine structures, 20(4), pp. 185201, (2007).

[6] B. Drew, A.R. Plummer, and M.N. Sahinkaya, "A review of wave energy converter technology". Sage Publications Sage UK: London, England, (2009).

[7] F. Antonio and O. Falcão, "Wave energy utilization: A review of the technologies", Renewable and Sustainable Energy Reviews, 14(3), pp. 899-918, (2010).

[8] I. López, J. Andreu, S. Ceballos, I.M. de Alegría, and I. Kortabarria, "Review of wave energy technologies and the necessary powerequipment", Renewable and Sustainable Energy Reviews, 27, pp. 413-434, (2013).

[9] H. Titah-Benbouzid and M. Benbouzid, "Ocean wave energy extraction: Up-to-date technologies review and evaluation", IEEE PEAC 2014, Shanghai, China, IEEE, pp. 338342, 2014-11-05, (2014).

[10] G.P.R. Papini, G. Moretti, R. Vertechy, and M. Fontana, "Control of an oscillating water column wave energy converter based on dielectric elastomer generator", Nonlinear Dynamics, 92(2), pp. 181-202, (2018).

[11] M. French, "On the difficulty of inventing an economical sea wave energy converter: a personal view", Journal of Engineering for the Maritime Environmental, vol. 220, no. 3, pp. 149-155, (2006).

[12]Ren21, Renewables-2018, pp.41, [Online].Available: $\quad$ www.ren21.net/wpcontent/uploads/2018/06/178652_GSR2018_FullReport_web_final_.pdf,[Ac cessed: 05- Feb.- 2019]. 
[13] Irena, International Renewable Energy Agency, [Online].Available: www.irena.org/publications/2018/Oct/Renewabl e-Energy-Outlook-Egypt, [Accessed: 15- Feb.2019].

[14] L. Rodrigues, "Devices for sea wave power extraction to electrical energy conversion", International Journal of Engineering and Industrial Management, vol. 3, pp. 193-210, (2010).

[15] L. Rodrigues, "Wave power conversion systems for electrical energy production", in Journal of RE\&PQJ, vol. 1, no. 6, p. 601-607, (2008).

[16] A. Muetze and J. Vining, "Ocean wave energy conversion - a survey", in the Conference of Industry Application IEEE, Tampa, Florida, October (2006), pp.1410-1417.

[17] R. Yeung, A. Peiffer, N. Tom and T. Matlak, "Design, analysis and evaluation of the ucberkeley wave-energy extractor", in the $29^{\text {th }}$ ASME International Conference on Oceans Offshore and arctic Engineering OMAE210, Shanghai, China, June (2010), p. 1-11.

[18] K. Khader, "Power Generation from Sea Waves Using Experimental Prototype of Wells Turbine or Suggested Special Rotating Mechanism", International Journal of Mining, Metallurgy \& Mechanical Engineering (IJMMME), vol. 3, , no. 3, pp. 161-166, (2015).

[19] C. Cargo, A. Plummer, A. Hillis and M. Schlotter, "Determination of optimal parameters for a hydraulic power take-off unit of a wave energy converter in regular waves", Journal of Power and Energy, Proc. IMechE, vol. 2263 Part A, pp. 98-111, (2011).

[20] A. Falcao and J. Henriques, "Oscillating-WaterColumn Wave Energy Converters and Air Turbines: A review", International Journal of Renewable Energy, vol. 3, pp. 1-34, (2015).

[21] J. Henriques, J. Portillo, L. Gato, R. Gomes, D. Ferreira and A. Falclao, "Design of OscillatingWater-Column Wave Energy Converters with an Application to Self-Powered Sensor Buoys", International Journal of Energy, vol. 112, pp. 852-867, (2016).

[22] K. Khader , M. El-Elimy and O. Nada, "MultiCriteria Selection and Improvement of Effective Design for Generating Power from Sea Waves", In the $20^{\text {th }}$ International Conference on Environmental Engineering and Protection (ICEEP'2018), Dubai, UAE, 22-23 January (2018), 20 (1) Part XIII, pp.1316-1326.

[23] S. Okamoto, T. Kanemoto, H. Bin and T. Umekage, "Flow around wells type runner installed in floating type unique ocean wave power station", Journal of Energy and Power Engineering, vol. 8, pp. 1974-1981, (2014).
[24]H. Polinder and M. Scuotto, "Wave energy converters and their impact on power systems", in International Conference of Future Power Systems, Amsterdam, Netherlands, November (2005), pp. 1-9.

[25] A. Garrido, M. Alberdi, I. Garrido and M. Amundarain, "Control of oscillating water column (owc) wave energy plants", Journal of Aout. XXXV Automatic, CEA-IFAC Valencia, vol. Sept., pp. 1-7, (2014).

[26]Z. Carija, K. Kranjsivic, V. Banic and M. Cavarak, "Numerical Analysis of Wells Turbine for Wave Power Conversion", Journal of Engineering Review, vol. 32, no. 3, pp. 141-146, (2012).

[27] M. Takao and T. Setoguchi, "Review article: air turbines for wave energy conversion", International Journal of Rotating Machinery, Hindawi Publishing, vol.1, pp. 1-10, (2012).

[28] S. Okuhara, M. Takao, A. Takami, T. Setoguchi, "Wells turbine for wave energy conversion improvement of the performance by means of impulse turbine for bi-directional flow", International Open Journal of Fluid Dynamics, vol.3, pp. 36-41, (2013).

[29] K. Takasaki, M. Takao and T. Setoguchi, "Effect of Blade Shape on the Performance of Wells Turbine for Wave Energy Conversion", International Journal of Mechanical, Aerospace, Industrial, Mechatronic and Manufacturing Engineering, vol.8, no. 12, pp. 2073-2076, (2014).

[30]C. Herron and C. Hicks, "The transfer of selected lean manufacturing techniques from Japanese automotive manufacturing into general manufacturing (UK) through change agents", Robotics and Computer-Integrated Manufacturing, vol. 24, pp. 524-531, (2008).

[31] P. Hines, M. Holweg, and N. Rich, "Learning to evolve: a review of contemporary lean thinking", International journal of operations \& production management, vol. 24, pp. 994-1011, (2004).

[32]E. Psomas and J. Antony, "Research gaps in Lean manufacturing: a systematic literature review", International Journal of Quality \& Reliability Management, (2019). https://doi.org/10.1108/IJQRM-12-2017-0260

[33] Y. Kazancoglu and Y. D. Ozkan-Ozen, "Lean in higher education: A proposed model for lean transformation in a business school with MCDM application", Quality Assurance in Education, Vol. 27 Issue: 1, pp.82-102, (2019). https://doi.org/10.1108/QAE-12-2016-0089

[34]L. R. LaGanga, "Lean service operations: Reflections and new directions for capacity expansion in outpatient clinics", Journal of Operations Management, vol. 29, pp. 422-433, (2011). 
[35] N. Piercy and N. Rich, "Lean transformation in the pure service environment: the case of the call service centre" International journal of operations \& production management, vol. 29, pp. 54-76, (2009).

[36] J. C. Chen and R. A. Cox, "Value Stream Management for Lean Office-A Case Study", American Journal of Industrial and Business Management, vol. 2, pp. 1-17, (2012).

[37] H. Wee and S. Wu, "Lean supply chain and its effect on product cost and quality: a case study on Ford Motor Company", Supply Chain Management: An International Journal, vol. 14, pp. 335-341, (2009).

[38] C. Keskin, U. Asan, and G. Kayakutlu, "Value stream maps for industrial energy efficiency", in Assessment and Simulation Tools for Sustainable Energy Systems, ed: Springer, pp. 357-379, (2013).

[39]E. Müller, T. Stock, and R. Schillig, "A method to generate energy value-streams in production and logistics in respect of time- and energyconsumption", Production Engineering, vol. 8, pp. 243-251, (2014).
[40] R. Schillig, T. Stock, and E. Müller, "Energy Value-Stream Mapping a Method to Visualize Waste of Time and Energy", IFIP International Conference on Advances in Production Management Systems, pp. 609-616, (2015).

[41] P. Halder and A. Samad, "Torque and efficiency maximization for a wave energy harvesting turbine: an approach to modify multiple design variables", International Journal of Energy Research, 41(7), pp. 1014-1028, (2017).

[42] M. Mohamed, Design optimization of savonius and Wells turbines, $\mathrm{PhD}$ Thesis, Magdeburg University, (2011).

[43] T. Hatsuzawa, A. Yamazaki, A. T.Nisisako, Y. Yanagida, "Design and evaluation of Artemiadriven micro ratchet gears", Journal of Sensors and Actuators A: Physical, vol. 235, no. 1, pp. 182-186, (2015). 